\title{
PUBLIC VS PRIVATE SECTOR OWNED URBAN PUBLIC SPACE PERFORMANCE IN TERMS OF USER PERCEPTION IN CITY OF COLOMBO
}

\author{
A.M. FAYAS ${ }^{1}$, M.T.O.V. PEIRIS ${ }^{2}$ \& K.G.P. KALUGALLA ${ }^{3}$ \\ 1, 2 Department of Town \& Country Planning, University of Moratuwa, Colombo, Sri Lanka \\ 1amohamedfayas11@gmail.com, ${ }^{2}$ vishvajithp@uom.lk, ${ }^{3}$ priyanga.kalugalla@gmail.com
}

\begin{abstract}
Public spaces are considered one of the fundamental elements in the urban context to promote leisure and recreation for urban dwellers. Public spaces contain variations within each other from the physical appearance, activities, and to usage factors. Private sector involvement for public space provision was increased in the recent past where public space ownership and access controls were shifted from solely public to private. This was criticized as privatization of public space and lead to debates on the decline of publicness and privacy of space. In this context, this research studied the public space from the user perception by considering publicly owned and operated versus privately owned and operated public spaces within Colombo, Sri Lanka. It is also explored the balance between ownership and access controls to determine the user preference in terms of the publicness features. User defined public space features were identified using 35 semi-structured interviews and 119 online questionnaire surveys. Qualitative analytic tools were used to evaluate the results including Content analysis and Space-shaper models with the support of NVivo software. The results revealed that publicly owned spaces were preferred by the users due to easy access and freedom for activities while privately owned spaces were preferred due to better infrastructure, safety, and security within. Also, it is identified that urban public space offered users the freedom to experience based on the levels of ownership and access controls. Finally, people preferred ownership by public over private sector as anecdotal evidence and values dominated in the public space attributes. This study provides key insights for planners to consider in the public space planning and the importance of private sector involvement and balance in the provision of optimal urban spaces in cities.
\end{abstract}

Keywords: Urban Public Space, User Perception, Ownership, Access Controls, Privatization

\section{Introduction}

\subsection{BACKGROUND OF THE STUDY}

Urban public space (UPS) is a vital element for basic human needs (Lopes, Cruz, \& Pinho, 2012). Traditionally public spaces in urban areas have provided by the government as a social welfare role. But the private sector intervention in public space provision is a recent trend visible in cities (Henry, 2008; Johnson \& Glover, 2013). Even though public space provision is a known urban regeneration strategy in many countries, it is often criticized as a privatization effort on freely accessible public spaces (Bandara, Silva, \& Navarathna, 2013; Madanipour, 2010; Torbati, 2018). This is no different in Sri Lankan context as private sector has intervened in more regulated spaces within commodified spaces in the form of shopping malls, plazas, and restaurants. But it is clear that general public tend to use such public spaces where public sector (government) led urban spaces proved to be less attractive comparatively (Nambuge, Peiris, \& Kalugalla, 2020). Privatization schemes have introduced commodity mix and access controls to regulate the users which raised concerns on the actual role of UPS in cities (Lopes, Cruz, \& Pinho, 2012; Chandrasekera, 2015). Historically, Jane (1961), Gehl (1971) and Lefebvre (1978) argued that public space use is determined by the user behavior and social interactions within the space. So, the UPS could be assessed from user perspective to determine the level of publicness within. This study attempts to 
understand the socio-political influence on publicness and the level of attraction caused by so called 'privatized' UPS in comparison with 'publicly' owned ones. Comparative case studies were selected from Colombo city as the private sector influence on UPS provision is largely seen in newly built commercial spaces.

\subsection{PROBLEM STATEMENT}

Urban public space is defined as the physically created space to mentally perceived space in different literature. Philosophers like Henri Lefebvre had argued that space is a mere social production instead of a physical construction (Schmidt \& Németh, 2010). In the dynamic urban context, socially governed principles by the community could be changing. In modern complexity of social perceived spaces, the question expected to seek answer is "would people prefer privately owned UPS over publicly owned UPS?". Based on the preferences, factors determine the attractiveness are important to study for planning of urban spaces. Therefore, this study compared UPS with different levels of publicness factors to identify dominant features of user preference. The objectives of this study were to understand the socio cultural and political factors determining the publicness of urban spaces and to evaluate the positive and negative impacts on users within each case study.

\section{Literature Review}

\subsection{CONCEPTIONS ON PUBLIC SPACE}

Public space terminology itself is derived towards the opposite of private space (Lopes, Cruz, \& Pinho, 2012) and targeted on for supporting the interests of public (Carr, Stephen, Francis, Rivlin, \& Stone, 1992). Due to the nature of the term, public spaces are considered as a provision made by the government with free access pass to general public (Leclercq, Pojani, \& Bueren, 2020; Németh \& Schmidt, 2011). Eventually public space has been shaped by the socio cultural factors to support the dynamic nature of human behavior (Crouch, 2006). Public spaces in Sri Lanka have been instrumental in the cultural context where village life had embedded publicness formed within religious and agricultural backbone (Chandrasekera, 2015). Due to the importance of public space for public health, Fredric Olmsted considered them as 'lungs of the city' (Schmidt \& Németh, 2010). The functional impacts and decline of public space were argued by Jacobs (1961), Gehl (1971) and Mitchell (1995) making public space debate a longstanding one.

In this context, private sector involvement in public space provision can be seen as a complementary effort to attract public for their business motives (Nambuge, Peiris, \& Kalugalla, 2020; Johnson \& Glover, 2013). Since public space is considered as a social production of users (Lefebvre, 1978), can the commodification be justified as long as the elements of publicness are there within the so called 'private spaces'? This question was answered in several viewpoints by the researchers. Leclerq (2020) studied the private sector involvement in terms of access, control, and behavior perspectives while access, agency and interest were identified as key differentiation factors by Benn and Gauss (1983). Even though arguments persist on such involvement as privatization of public rights, its development must be viewed from the form, functions, and sustainability perspectives (Carmona, Magalhães, \& Hammond, 2008; Kettaf \& Moscarelli, 2004; Schmidt \& Németh, 2010). Since the privately operated spaces are contested to generate common ground with public spaces, this research expects to view its importance in place making of urban areas in cities.

It is identified that there is a gap available to understand and view public space in cities from user perspective (Henry, 2008). There are different ways that researchers have illustrated on the use of public space from its form and functional characteristics. Colquhoun (1989) defined the term urban space into two senses as social space and built space. Sociologists and geographers study the social space as the impacted spatial entity because of social interactions. In this view, physical activities are identified because of cognitive activity. The other view is that social behavior is characterized the physical space as per the design elements which is commonly identified by urban and landscape designers. The morphology of the space as the driving force of public perceptions and how it is used generate the meaning of the space (Leclercq, 2018). Henry Lefebvre (1978), proposed the public space as social production where Marxism influence was given for public space provision. Lefebvre followed Marxism approach to recognize the public space as a container of social activities to produce spatial practice (Kilian, 1997). This perception led to view public space as a socio-political product in urban areas and opened multidisciplinary focus on identifying the public space through power, race, gender, identity, and public interpretation (Chandrasekera, 2015; Varna \& Tiesdell, 2010). Also, the socio economic and market-based factors shaping 
public space have given pathway to view public space as a commodity. Urbanization led dynamic socioeconomic conditions have caused the researchers to view alternative factors within public spaces as determinant factors. Ownership, control, civility, access, and animation are considered a few factors to identify the publicness of public spaces in modern world (Schmidt \& Németh, 2010).

\subsection{PUBLICNESS OF URBAN PUBLIC SPACE}

It is known that public spaces create a sense of place for community in the urban context (Inroy, 2000). Management of Urban Public Spaces (UPS) brings extra attention on this scenario as the space provision is controlled and managed by owners who can decide upon the acceptable uses, users, and behaviors. But there is a clear difference in physical and functional activities as public space is managed by private or public entities. With the modernization, public spaces required to consider safety and security of its users in provision of public services (Kilian, 1997). In such situation, it is known that required safety and security features at UPS would come at a cost. With the budgetary limitations for management of urban spaces by the government (in Sri Lankan context), private sector could be a potential candidate to add commodity mix and provide such requirements (Henry, 2008). Therefore, private sector contribution in ensuring the sustainability of public spaces is an important consideration to remember. Often, cash-strapped municipal governments provide encouragements, to the private sector in exchange for the provision and management of public space (Schmidt \& Németh, 2010).

Ownership of public spaces is a decisive factor in determining the accessible users and management functions of each entity (Németh \& Schmidt, 2011; Carmona, Magalhães, \& Hammond, 2008). The regulated use of public space and commodification of specific functions have been common externalities caused by such interventions. Although privatization efforts could violate the fundamental attributes of public space use, there is a tendency for public to use such spaces within shopping malls and arcades (Nambuge, Peiris, \& Kalugalla, 2020; Leclercq, Pojani, \& Bueren, 2020). The same reasons have created public space provision by private sector promoted by governments as an urban regeneration strategy (Roberts \& Sykes, 2008). In Sri Lanka, government have also provided operation and maintenance tasks of recently developed state owned public spaces such as Arcade Independence Square (Colombo 07), Dutch Hospital Complex (Colombo 01) and Boardwalk by Waters Edge at Diyatha Uyana (Battaramulla) as exchange provision. This exchange greatly enlarging the amount of publicly accessible space in major urban areas (Schmidt \& Németh, 2010). In some situations, certain public spaces were rejected by public while some places are admired and used. Therefore, public space must facilitate the user needs in a city as interaction among diverse set of users and inclusive features cannot be forced upon the owners or managers of public space (Franck \& Paxson, 1989; Kohn, 2004). Some researchers have argued that 'publicness' could easily be lost in such quasi-public spaces or artificial elements (Varna \& Tiesdell, 2010; Franck \& Paxson, 1989) while another set said that such interventions are necessary to balance the dynamic social structure in city scale (Kohn, 2004; Johnson \& Glover, 2013). This research has focused upon the latter argument of publicness as a phenomenon created by users and tested its need in the urban context. In such situation, user groups might not be controlled by the owners, but the users themselves.

\section{Method And Materials}

The research followed qualitative research methods to assess the user perception on the use of UPS. The access controls and regulations directed by the specific ownership groups are well affected on the user behavior and the perception on public space use. The research considered stakeholder categories including, public space users and providers, planning and regulatory agencies, urban designers, and infrastructure agencies.

First, theoretical understanding was obtained through extensive literature on public space provision ranging from the fields of urban design, planning and sociology. Key theoretical and empirical developments proposed by Lynch (1960), Jacobs (1961) and Gehl (1971) against the Lefebvre (1978) in identifying UPS in cities and its functional aspects were considered. Secondly, the key elements of urban public space from user access and control perspectives were applied in urban context based on the attributes identified in literature review. By assuming the social status, personal preferences and complementary activities encouraging the users to visit UPS as static, ownership and access controls-based regulations were given priority in identifying the publicness within. The abstract case studies were selected based on the classification in Table 1 as developed by Torbati (2018) according to public space management functions. 
Thirdly, the framework was tested in a selected two (02) case studies in Colombo city. For the assessment of publicness features of UPS in the city, a fully publicly owned space and fully privately-owned space were selected for the comparison of features, Galle Face Green (GFG) which is fully access to public and managed by public sector and Excel World Entertainment Park (EWEP) which is fully privately owned and operated were selected to test the research question. Even though GFG has unlimited access and EWEP has strict limited access for public functions as well as heterogeneous activities within, the study focused upon the determinant factors for users to use the specific space. The attributes defined by the general public to use these UPS was aimed as the case studies considered were the first of such kinds in Colombo. Also, comparatively these case studies were identified as major public spaces in terms of the use, users, ownership, access, and availability based on online questionnaire survey. Public interviews were conducted at each location to identify the publicness factors and the preferences on use of each space within.

\begin{tabular}{|l|l|}
\hline Category & Description \\
\hline Public spaces & $\begin{array}{l}\text { urban spaces accessible for public and fully owned and operated by the } \\
\text { government agency or entity }\end{array}$ \\
\hline Private spaces & $\begin{array}{l}\text { Special public spaces designed for special and completely private group. The } \\
\text { owners can determine the users with full restricted access. To enter such } \\
\text { places, public need special permission or paid tickets. }\end{array}$ \\
\hline
\end{tabular}

Table 1: The urban space classification

(Source; (Torbati, 2018))

Due to COVID-19 pandemic, a limited response was received from the in-site questionnaires from users as 09 responds from GHG and 08 responds from EWEP were obtained. In addition, 119 responds were obtained from online questionnaire surveys. Another limitation was the consideration of prepandemic situation for questionnaire survey might have led to misinformation by the responders. The results were used to differentiate the user preferences and to understand the role of private sector in creating public spaces in cities.

\section{Analysis and Discussion}

The content analysis was conducted by using NVivo software for the coding process to identify user preference. SPSS tool was used to generate descriptive analysis of users under each case study. Literature review, semi structured interviews and online questionnaire survey were sourced to achieve the objectives of this study. Overall, in the survey, 75 percent of users are classified under 18 to 35 years of age in which majority have used the GFG as its free access UPS known by all. This section comprised of the analysis of user profile, physical features of UPS and the key attributes as identified by the user perception surveys. The findings were then used to determine the level of impact from access and control attributes.

\subsection{DESCRIPTIVE STATISTICS}

\subsubsection{Online questionnaire survey}

Online survey was intended to obtain the specific user profile of each UPS, specific spatial and temporal attributes within the UPS to use or not to use, user-based specific factors to sense the UPS (personal factors) and focused areas of improvements necessary within the UPS to use in future.

For the online survey, $54 \%$ of the participants were Female and over $90 \%$ of the responders were in between the age group of 18 to 55 years. $77 \%$ were less than 35 years of old and majority have visited the locations with their friends and family. Young age group prefer EWEP than GFG due to the privacy of the place and the multiple activities, although above mentioned group of people use those places using money because of their high social status. So EWEP show case the social segregation while the usage. Considering the visit of both place, family wise visiting and gathering were taken place at GFG because of the easy access and identity of the place.

Figure 1 interprets the visits made by users in each case study areas in a Likert Scale. 1 means very low frequency while 5 means very high frequency of visiting each public space. The results show that 
majority have visited Galle Face Green on comparatively high frequency while Excel World Entertainment Park was seldom visited by the responders. The information in Figure 2 was used to refine the comments given for each case study by the responders since frequency of travel has considered as an attribute of the user preference of each public space. Considering the majority of responders used GFG, Figure 2 shows that about $60 \%$ of users travel to GFG frequently while only $87 \%$ of responders travel seldom to EWEP. Therefore, the attributes for privately operated UPS were mostly defined by using interviews conducted on site.

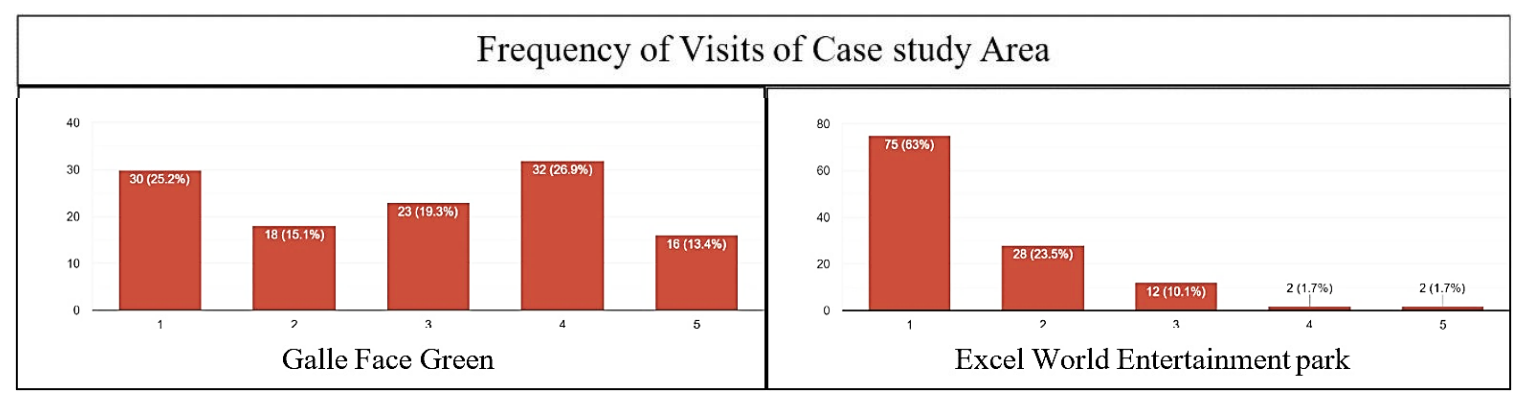

Figure 1: Frequency of visit by the users (Source: Author)

\subsubsection{Semi-Structured Interviews}

Interviews were conducted by using judgmental sampling method and completed over a period of four weeks, based on the author observations, three user categories were identified as family groups, similar age friends and young couples. To obtain an optimum output, the interviews were conducted within relevant group of people in every age category. Out of the sample, $70.6 \%$ of interviewees were in between the age of 18 to 35 years. Gender distribution was maintained equally and $76.5 \%$ of the responders were single. About $64 \%$ of the responders have visited the public space on weekly or monthly basis, information of the responders was similar as the results of online questionnaire survey responds. There is a significant relation between age, marital status and Campanians (with whom) because 18 to 35 age group comparatively not married and coming with friends group, it leads the modern change in public space provision (Schmidt \& Németh, 2010).

\begin{tabular}{|l|l|c|c|}
\hline Categories & Description & Frequency & Percentage (\%) \\
\hline \multirow{4}{*}{ Gender } & Male & 8 & 47.1 \\
\cline { 2 - 4 } & Female & 9 & 52.9 \\
\cline { 2 - 4 } & Less than18 & 1 & 5.9 \\
\cline { 2 - 4 } & 18 to 35 & 12 & 70.6 \\
\cline { 2 - 4 } & 36 to 55 & 2 & 11.8 \\
\cline { 2 - 4 } & above 55 & 2 & 11.8 \\
\hline \multirow{4}{*}{ Farital Status } & Yes & 4 & 23.5 \\
\cline { 2 - 4 } & No & 13 & 76.5 \\
\hline \multirow{5}{*}{ With whom } & Once a week or more & 1 & 5.9 \\
\cline { 2 - 4 } & Once a month & 6 & 58.8 \\
\cline { 2 - 4 } & Rarely & 1 & 35.3 \\
\cline { 2 - 4 } & Alone & 5 & 5.9 \\
\cline { 2 - 4 } & With family members & 11 & 29.4 \\
\cline { 2 - 4 } & With my friends & 6 & 35.7 \\
\hline Mode of Transport & Bus & 5 & 29.4 \\
\cline { 2 - 4 } & Own vehicle & 65.3 \\
\cline { 2 - 4 } & Three-wheeler/ taxi & 6 & \\
\hline \multirow{5}{*}{} & & & \\
\hline
\end{tabular}

Table 2: Semi structured interview

(Source: Author) 


\subsection{OBSERVATION STUDY}

Direct observations of the public spaces in two case studies have showcased the identifiable differences between publicly and privately-owned spaces, based on the physical appearance characteristics and identical elements within. Figure 3 shows the differences in terms of entrance, basic facilities, and seating within each UPS from physical elemental setting.

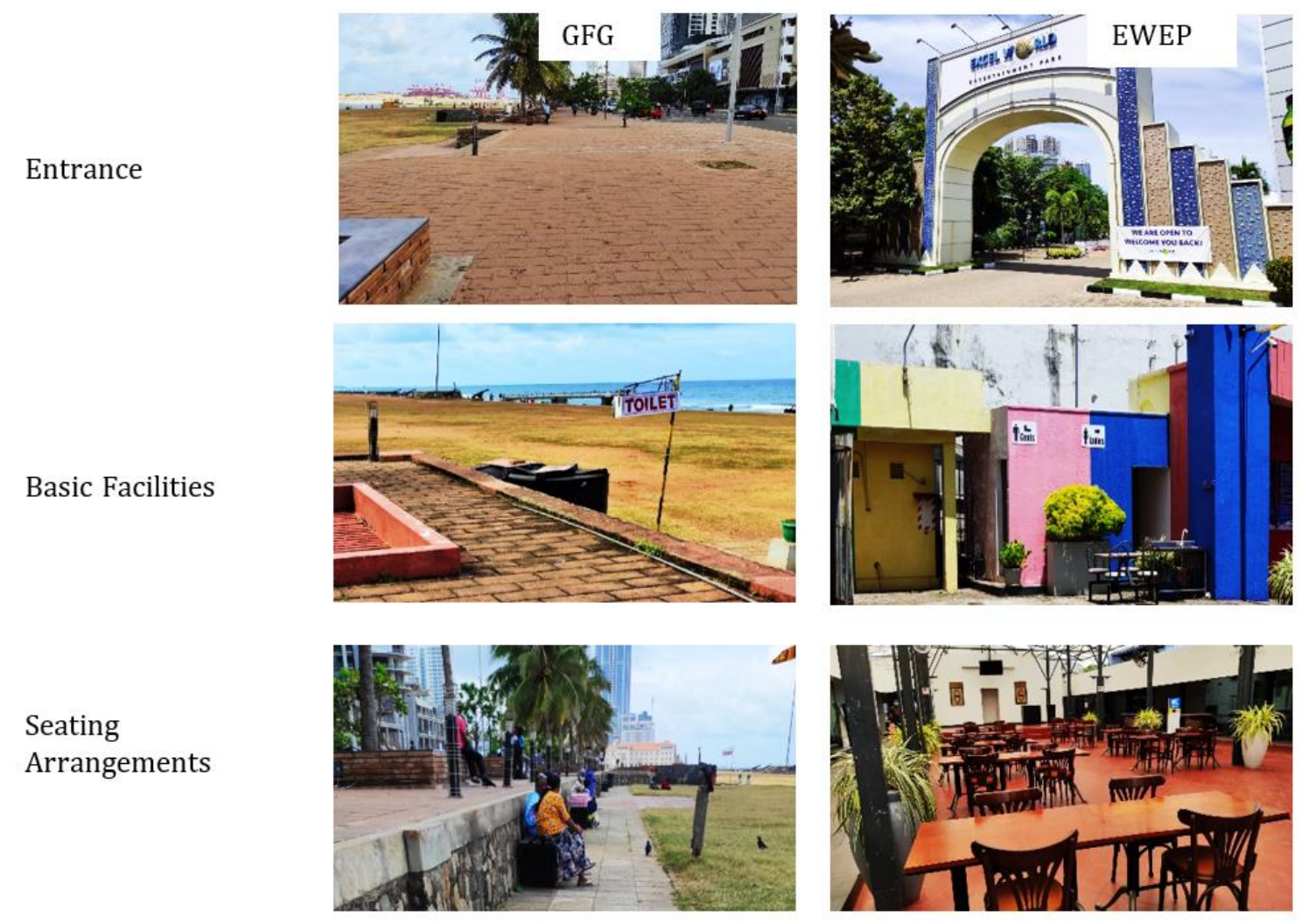

Figure 2: Observation photographs

Figure 2 shows the significant differences in terms of physical appearance which is affected by the setting of each UPS. GFG is an open public space as compared to enclosed EWEP. Therefore, EWEP used physical elements to support its commercial needs as well as to provide the best possible experience for users. Regardless of open or closed UPS, the specific elements compared in Figure 3 show the effort by EWEP in making their own identity within the city. Unique structure at the entrance will be the first impression for users and act as an identity and translate its power to the user's mind. Also, the painted wash rooms are easy to differentiate and followed the theme of EWEP so users sense the location and identity. These are always possible to follow in GFG regardless of its context. Unique identity of the UPS and design elements within the UPS can add the heterogeneity and in turn improve the user experience and image of the place. At the same time, physical appearance of GFG provides the openness or inclusiveness or the space and by contrast EWEP is an exclusive entity. But still internal utilities and spaces were highly contrast to each other based on observations. Sanitary facilities and seating arrangements have shown a clear difference in both cases where cleanliness and privacy were well served at EWEP.

\subsection{DETERMINING FACTORS OF PUBLICNESS}

The user perception is an important viewpoint to understand and delineate the UPS. To understand how public spaces perceived by people, the users were requested to provide a comparative feedback of case studies based on two or more public spaces visited before the COVID-19 pandemic situation. In general, all the participants were asked on the reasons for public space use and thereby developed the word cloud analysis based on the responses. Figure 4 shows the results of word cloud analysis.

Accordingly, it revealed that people mostly attracted by food, shops and play which depicted that restaurants, variety of commercial activities in the form of shopping centers as well as recreation spaces were the priorities of users. So the UPS which can provide competitive advantage over these conditions 
would be attractive for the users. GFG lacks a few elements as expected by the users from the UPS. Relaxation, visiting with friends and family were secondary important points of attraction. The following statement was given by a respondent from EWEP,

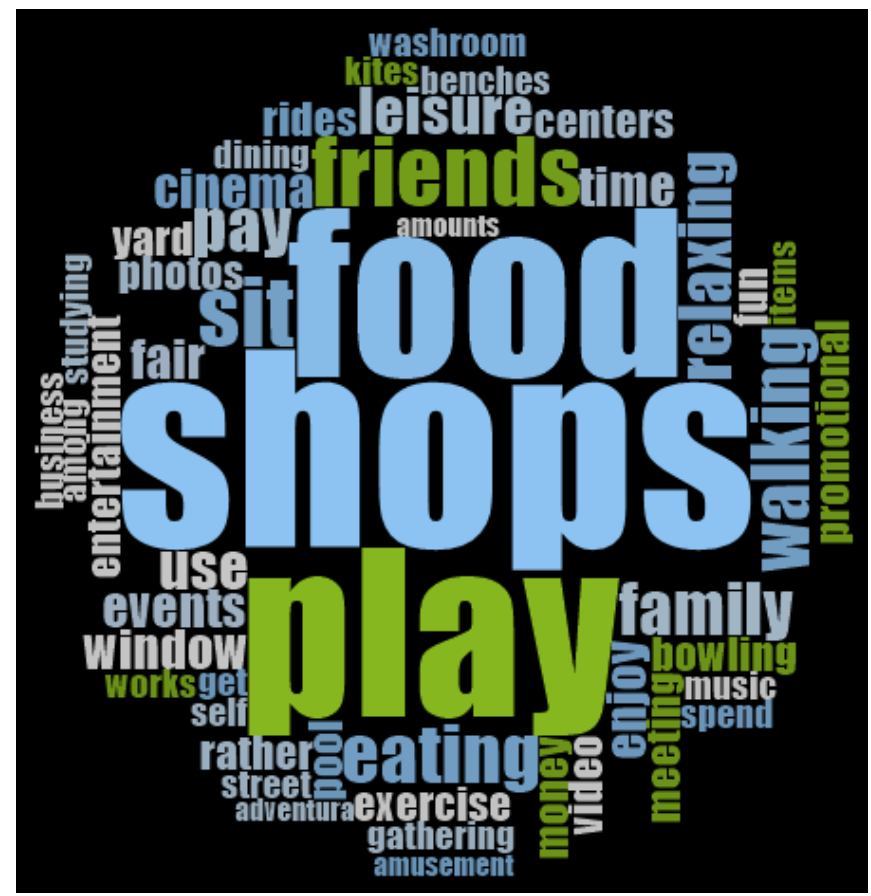

Figure 3, User perception of UPS

(Source: Survey and interview findings by author)

"That [EWEP] was good. Rather than other public spaces, this one is good in enjoyment perspective, there are more fun activities. Children will really enjoy this place." (Respondent 3 )

The range of play areas within EWEP covered different user groups with exclusive features to enjoy while GFG had unregulated activities as users can make their own fun space. Both methods contain its own advantages and unregulated activities could not support the inclusive access for some user groups in GFG as some games played by youth were disturbing the other users such as Cricket and Flying Kites.

The factors which determine the public space and its publicness based on user preference is an important viewpoint in this research. There are number of research and journals mentions the UPS determinant factors but considering Sri Lankan context those factors divided as positive and negative based on public perception. Modified version of Radar diagram based on Space-shaper Model indicating key differences between state (public) and privately-owned spaces. The positive side indicated features with more publicness base and at the same time negative side indicated features with less publicness (Privateness). Privateness indicated as a new word in this article, considering the degreasing level of publicness encourage the increasing level of privateness.

Radar diagram (Figure 4) depicted the variation between public spaces based on determinant factors which derived from public opinion. Accordingly, many positive aspects were covered by public ownership features and vice versa. So, it clearly depicted that publicly owned spaces depicted more publicness as compared with private sector.

From positive aspect, privately owned UPS tend to have provided more comfort, safety and security for the users compared with state owned spaces while availability of common activities and accessibility were positive features of publicly owned UPS. Similarly private UPS were not affordable, restricted access and promoted social segregation while common criticism for publicly owned spaces were limited facilities and lack of safety and security. This revealed that both the spaces have pros and cons in terms of capturing user attention and users attached to specific UPS. The statements from the users have validated the reasons for the preferences or lack of preferences for the use of public spaces where ownership has not been the major 
concern, but the expected facilities and amenities. But ownership has been the key determining factor for the level of service to provide food, play and shop options.

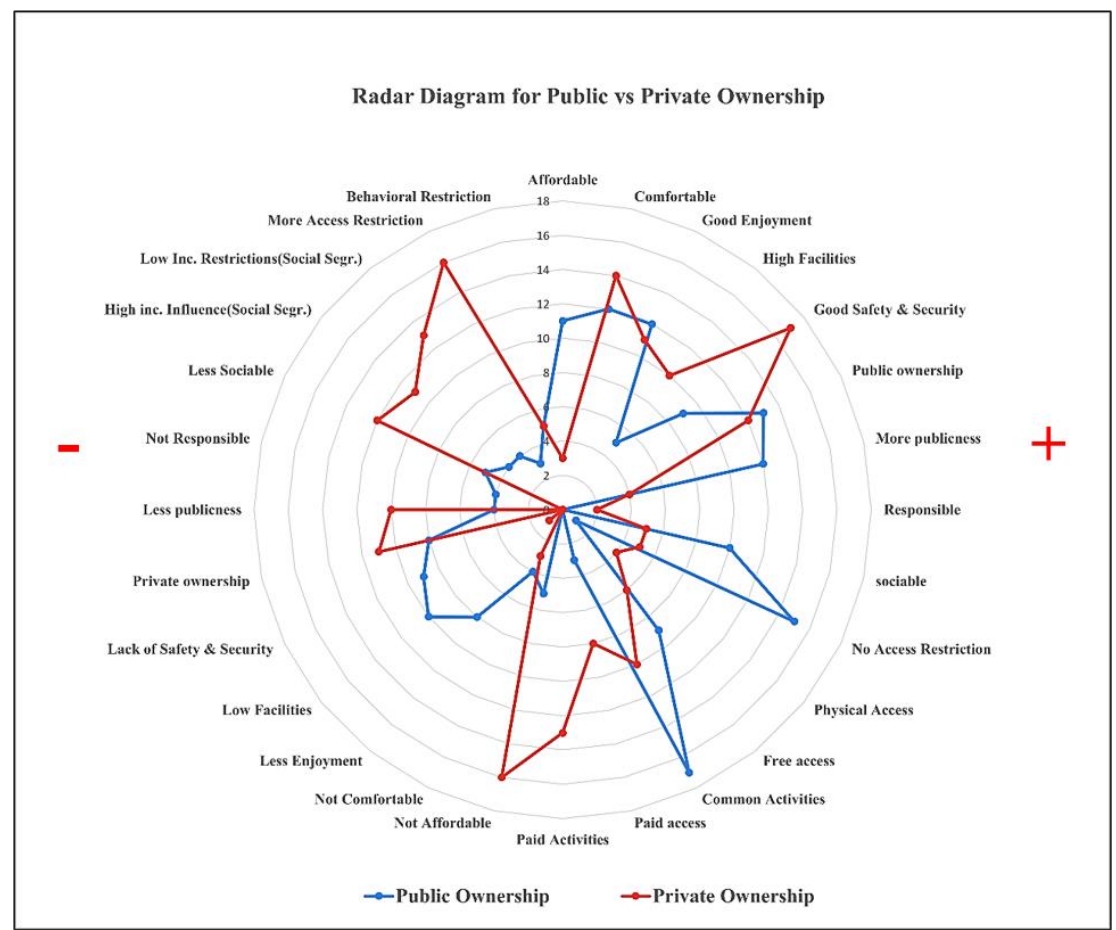

Figure 4: Radar Diagram for public vs private UPS

Following statement was mentioned by one of the respondent from GFG ,

"If we need to relax or spend our leisure time we have to go to any kind of place, so the difference is if we have money, we can enjoy the time and we can enjoy some games in private places, but if considering public owned spaces, we can do those without money. So, money is the difference between that. There is a problem in public space is the facilities and maintenance. Because the private sectors are maintaining the spaces better than the government. So, I prefer public-owned spaces with enough facilities, and they should provide proper safety and securities." (Respondent 4)

According to the statement, an important consideration on social segregation raised. Do we need money to use public space? The answer can be 'Yes' and the same time 'No'. Can government provide all these facilities free of charge for the public? Or should they? The dilemma faced by state-controlled UPS were to manage these spaces without proper financial allocation or income. The management of functions are comparatively successful for privately operated UPS due to effective mix of freedom, access control and utilities. This viewpoint revealed the importance of activity and business mix in UPS in cities.

\subsection{PUBLIC PERCEPTION ON PUBLIC VS PRIVATE OWNED SPACES}

Public perceived the UPS based on their understanding of the place, mainly through users and uses of the place. According to the public opinion, the aspects are different in both spaces based on same characters (factors). All factors showcased different notions and themes. The charts automatically arrange the sizes based on the perception of the people (larger the size, higher the importance and different colors to differentiate the factors), in that case Access is the major factor and there is no access restriction in GFG depicted under that factor.

This hierarchy chart (figure 5) shows how people understand the determinant factors and how public concluding based on factors. public opinion depicted based on influencing factors, here Access, Ownership, feeling of safety are the front-line influencing factors in public owned spaces.

"Safety is not here. There many issues happening every day, when considering night time, it will create maybe more security and safety problems. There is no proper lighting inside the Galle Face [Green]. Sometime pick 
pocketers and drug addicts related cases also happening here. So, in the sense of safety and security, this place is not suitable" (Respondent 5)

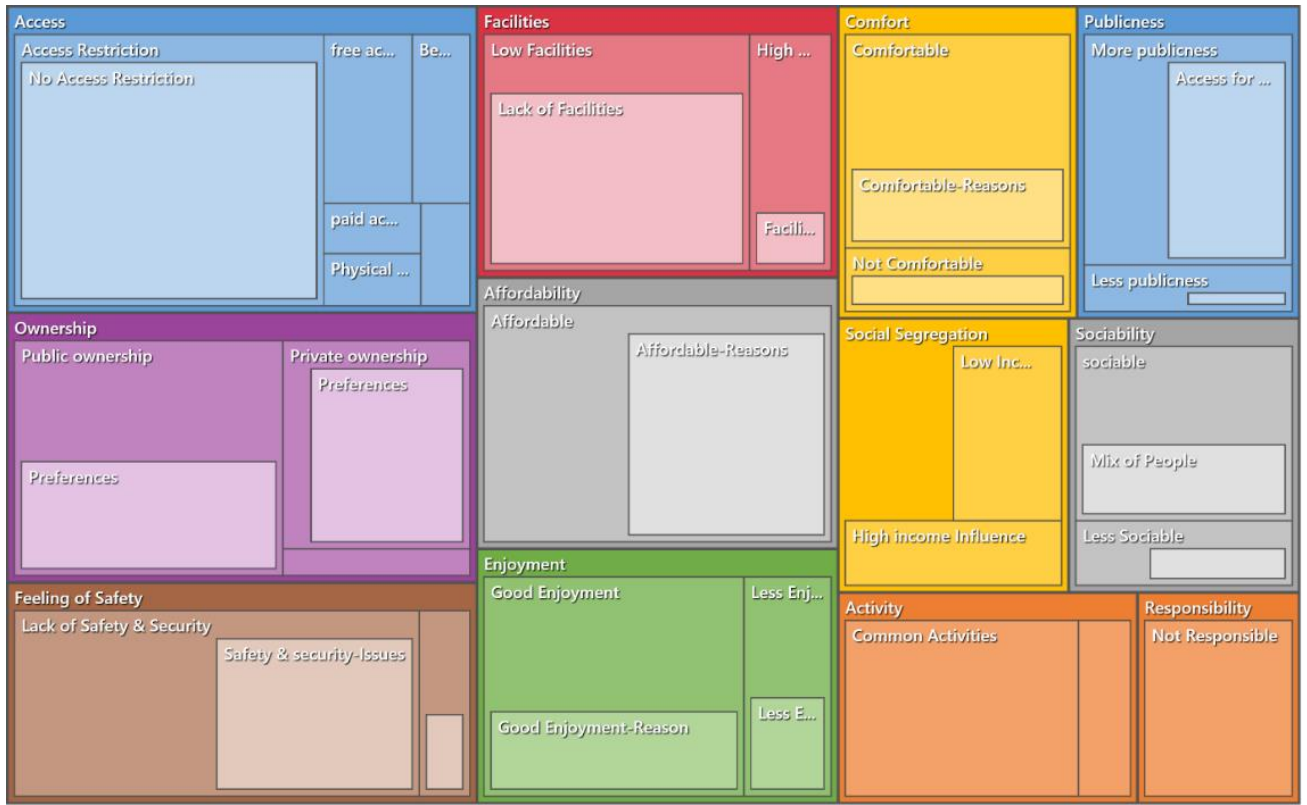

Figure 5: Hierarchy Chart - Galle Face Green

Above statement clearly showcases the current issues in state owned public spaces. There is no access restriction and public prefer public ownership, but the safety is lack, and low facilities so it is showcase in frontline influencing factors prompting on people's desires. So, when this kind of factors increasing it will reduce the attraction on public owned spaces.

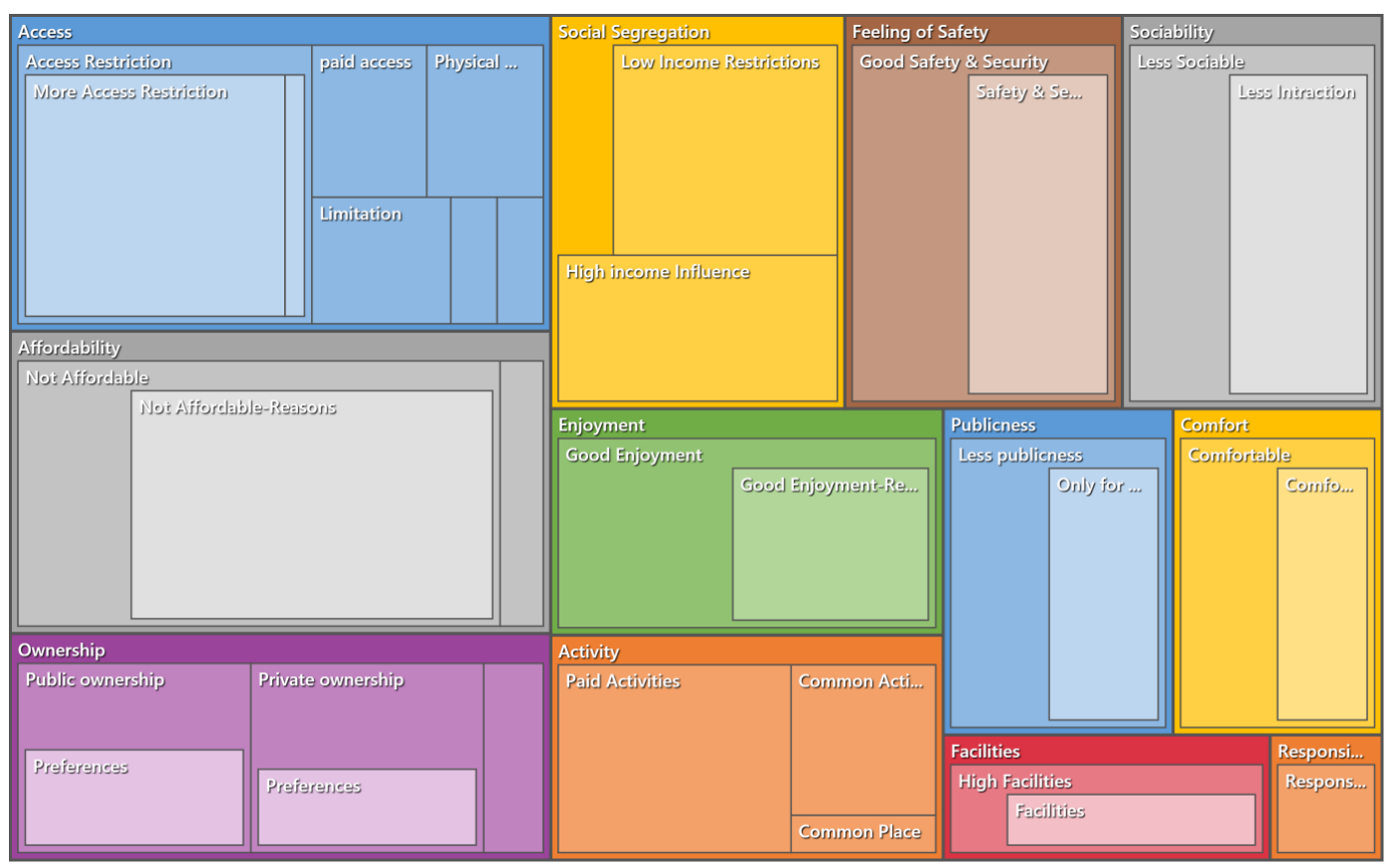

Figure 6: Hierarchy Chart - Excel World Entertainment Park

Considering private owned space factors, Access, Affordability, and ownership are the most influencing factors as mentioned in figure 6. More access restriction and no affordable with private ownership are the public opinion and it will also reduce the attraction in private owned spaces, but these notions emerged because of business motives of private owned spaces. Enjoyment and good safety will attractive more people on private spaces but as mentioned in following statement some of the characters degreasing attraction on private spaces. 
"If you want to enter this place you need to show your identity because they will ask why you came here? if we want to enter inside the place, we need to spend money without money we cannot do anything. Even though if you need to enter inside the entrance, you cannot carry any food or drinks so that kind restriction also there. Consider this place into Galle face it has more restrictions." (Respondent 5)

Factors/Themes

Ownership/Control
Access
Enjoyment
Activity
Sociability
Publicness
Feeling of safety
Affordability
Comfort
Facility
Social segregation

Responsibility
Excel world

Galle face

\begin{tabular}{|c|c|}
\hline $\begin{array}{l}\text { Private ownership and public } \\
\text { ownership }\end{array}$ & Public ownership and Private ownership \\
\hline More access restriction & $\begin{array}{l}\text { Access restriction is not there it is open } \\
\text { for all (much better) }\end{array}$ \\
\hline Much better for Enjoyment & Enjoyment is good with some issues \\
\hline Most of them are Paid activities. & Common place with free activities. \\
\hline This place is less sociable. & This is good in sociability. \\
\hline Publicness is very less & More Publicness \\
\hline $\begin{array}{l}\text { safety and security are much } \\
\text { better here }\end{array}$ & $\begin{array}{l}\text { safety and security not good, it is very } \\
\text { less here. }\end{array}$ \\
\hline $\begin{array}{l}\text { Not affordable to anyone without } \\
\text { money. }\end{array}$ & affordable to everybody \\
\hline comfortable for users & comfortable for users \\
\hline good facilities indicated. & good facilities indicated. \\
\hline $\begin{array}{l}\text { This place highly suggested for } \\
\text { High income category and there } \\
\text { are low income restrictions }\end{array}$ & $\begin{array}{l}\text { This place highly suggested for High } \\
\text { income category and there are low } \\
\text { income restrictions }\end{array}$ \\
\hline Responsible to users & Not Responsible to users \\
\hline
\end{tabular}

Table 3: Table User reviews on UPS determinant factors (Source Author)

Hence, table 3 revealed the positive and negative aspects in both public and private spaces and people expecting a change in UPS to create sustainable and user-friendly public spaces in urban areas.

\section{Conclusion and Recommendations}

Provision of urban public spaces has been dominated by the private sector in the recent past as compared to long term dominance by the public sector in the history. This study compared unique attributes within privately owned and operated spaces as against the publicly owned and operated ones. Publicly owned spaces are more inclusive in sense where every city user can enter or exit, enjoy and play without restrictions as followed by the general norms and conditions. Privately-owned spaces provide safety, security, modernity, and psychological attraction for users which is not as effectively as available in publicly operated spaces. In addition, people tend to visit for shopping purposes to newly emerged public spaces within shopping malls and plazas which provide commodification blend in UPS. In addition, one of the most important findings of the research was that users preferred the control actions by privately owned UPS due to safety purposes and social status identification. Even though inclusivity was identified as a determinant factor for publicness (Bandara, Silva, \& Navarathna, 2013; Leclercq, Pojani, \& Bueren, 2020), access controls were considered useful to ensure the freedom and safety within. Also, it is revealed that people prefer publicly owned UPS over privately owned as a whole which exposed vital cognitive elements on sense of freedom within public space.

One of the objectives of this study was to understand the public space and its function in urban context. Observations and word cloud analysis revealed that restaurants, shopping space, relaxation and recreation were the main reasons for people to visit UPS. Shop, play and food are most determinant factors for people to use UPS where GFG had not offered all of these up to the expected levels of the users. Inclusivity itself have imposed restrictions to enjoy and experience the publicly owned spaces which brings 
back to the question that how inclusive the UPS should be? Users preferred the environment as easily accessible, enjoyable with entertainment and availability of clean sanitary facilities. At the same time, less access restrictions, sufficient safety and security, cleanliness, and peaceful public spaces are expected by the users including the functional needs such as walking, sitting, studying, relaxing, eating, social events, gatherings with family or friends, etc. These were varied in case studies due to the ownership and access variations. GFG as an open public space, was preferred by users due to minimum restrictions for users at any time. On the other hand, private spaces have preferred by the users since privateness was more important for them. This is an important finding where the paid entrance was considered a freedom to use the space for specific users. Users at EWEP highlighted that paid entrance provided the ownership sense for users as no controls were there to use the UPS. Therefore, privately owned spaces provided the needed privateness as users expect minimum disturbances which is highly unlikely in a publicly owned space.

The privacy and the publicity also identified through analysis, as Deutsch (1992) argued the private (privacy) public spaces exclude access because high access restriction at the same time public (publicity) gain the access by less access restriction. So, expected user groups were different in each category and additional indicators like economic status of people, law and order in the city could be determined factors for the attraction of people into UPS. This study provides important findings for town planners and policy makers to identify the importance of public space provision by private sector in the urban context. Urban planners and designers can focus on public and private participation (PPP) models as a hybridization for UPS through effective regulation and frequent monitoring of the outcome (Varna \& Tiesdell, 2010). Also, it was revealed the importance of the user perception on public space provision which needs special attention in the pre and post planning stages. This research could be further expanded by undertaking physical, spatial, and economic indicators to observe the behavior of UPS users to determine the needed changes/ modifications of public space in cities as well as to propose variety of UPS types to implement in different spatial conglomerations of cities. And a further study is required to assess the social segregation through privatization of public spaces from two perspectives, first from what activities and utilities could be free and what not. The second is the management model of commodification structure as the role of state in regulating such spaces from beneficial perspective of people as users. Finally, the cognitive behavior of people can be dynamic so the expected facilities, behavior and functions of urban public spaces will be a temporal measure in cities.

\section{References}

Bandara, V., Silva, V. D., \& Navarathna, D. (2013). . Perception of "publicness" of the public spaces with special reference to public parks in colombo and sri jayewardenapura. Cities, People Places, 1-25.

Benn, S., \& Gaus, G. (1983). Public and private in social life. Taylor \& Francis.

Carmona, M., Magalhães, C. d., \& Hammond, L. (2008). Public Space- The management dimension. New York: Taylor \& Francis e-Library.

Carr, S., Stephen, C., Francis, M., Rivlin, L., \& Stone, A. (1992). Public Space . Cambridge University Press.

Chandrasekera, T. (2015). Rejuvenating Dysfunctional Public Spaces Using Augmented Reality Systems (ARS). American Journal of Mobile Systems, Applications and Services, 1, 64-76.

Colquhoun, A. (1989). Modernity and the Classic Tradition. Architectural Essays, 1980-1987.

Crouch, D. (2006). Geographies of leisure. A handbook of leisure studies , 125-139.

Deutsche, R. (1992). Art and public space: Questions of democracy. Social Text, 33, 34-53.

Fernando, N. A. (2006). Open-ended space, Loose Space: Possibility and diversity in urban life. Routledge.

Franck, K., \& Paxson, L. (1989). Women and urban public space. Public places and spaces, 121-146.

Gehl, J. (1971). Life between buildings: using public space. Island press.

Glover, T., \& Burton, T. (1998). A model of alternative forms of public leisure services delivery. Leisure management: Issues and applications, 139-155.

Henry, S. (2008). Convivial urban spaces : creating effective public places. London: Earthscan.

Inroy, N. (2000). Urban regeneration and public space: The story of an urban park. Space \& Polity, 4(1), 23-40.

Jacobs, J. (1961). The death and life of great American cities. New York: Vintage.

Jacobs, J. (1961). The death and life of great American cities. New York: Vintage.

Johnson, A., \& Glover, T. (2013). Understanding Urban Public Space. Leisure Sciences: An Interdisciplinary, 190-197.

Kettaf, F., \& Moscarelli, F. (2004). Understanding Public Space Concepts as Key Elements of Sustainable Urban Design.

Sustainable Architecture and Urban Development, 229-244.

Kilian, T. (1997). Public and Private, Power and Space. Rowman \& Littlefield, 1997.

Kohn, M. (2004). Brave new neighborhoods: The privatization of public space. . Psychology Press.

Leclercq, E. (2018). Privatisation of the Production of Public Space. London: Architecture and build environment. 
Leclercq, E., Pojani, D., \& Bueren, E. V. (2020). Is public space privatization always bad for the public? Mixed evidence from. Elsevier, 1-11.

Lefebvre, H. (1978). De l'état (Vol. 4). Paris: Union générale d'éditions.

Lopes, M., Cruz, S., \& Pinho, P. (2012). The changing publicness of urban spaces. EURAU 12 - European Symposium on Research in Architecture and Urban Design. Porto: EURAU. doi:10.13140/RG.2.1.4161.0960

Lynch, K. (1960). The image of the city (Vol. 11). Cambridge: MIT press.

Madanipour, A. (2010). Whose public space. Whose Public Space. International Case Studies in Urban Design and Development.

Mitchell, D. (1995). The end of public space? People's Park, definitions of the public, and democracy. Annals of the association of american geographers, 85(1), 108-133.

Nambuge, G. S., Peiris, M. T., \& Kalugalla, K. G. (2020). Assessment of urban public spaces within shopping malls: youth perspective in the city of colombo. International Journal of Real Estate Studies, 14(2), 28-38.

Németh, J., \& Schmidt, S. (2011). The privatization of public space: modeling and measuring. Environment and Planning : Planning and Design, 38, 5-23.

Oldenburg, R. (1999). The great good place: Cafes, coffee shops, bookstores, bars, hair salons, and other hangouts at the heart of a community. New York: Da Capo Press.

Rapoport, A. (1977). Human Aspects of Urban Form. Oxford: Pergamon Press.

Relph, E. (1976). Place and placelessness (Vol. 67). London: Pion.

Roberts, P., \& Sykes, H. (2008). Urban regeneration: A handbook. SAGE Publications Ltd. doi:10.4135/9781446219980

Schmidt, S., \& Németh, J. (2010). Space, place and the city: Emerging research on public space design and planning. Journal of Urban Design, 15(4), 453-457.

Sennet, R. (1974). The Fall of Public Man . New York: WW Norton \& Company.

Slack, T. (1999). Changing boundaries and new management implications for leisure organizations. Leisure studies: Prospects for the 21st century, 399-434.

Torbati, H. (2018). The Role of Environmental Graphic in the Identification of Urban Public Spaces. Civil Engineering Journal, 1-6.

Varna, G., \& Tiesdell, S. (2010). Assessing the publicness of public space: The star model of publicness. Journal of Urban Design, 15(4), 575-598. 